\title{
Freedom of expression and the media reality in Republic of Macedonia
}

\author{
Liljana Siljanovska \\ South East European University, Tetovo, Republic of Macedonia
}

Email address:

siljanovska2002@yahoo.com(L. Siljanovska)

\section{To cite this article:}

Liljana Siljanovska. Freedom of Expression and the Media Reality in Republic of Macedonia. Social Sciences. Vol. 2, No. 3, 2013; pp. 97-104. doi: 10.11648/j.ss.20130203.11

\begin{abstract}
Tools for mass communication influence on creating and channeling of public opinion for every segment of social life; in era of globalization they erase the borders of events in sphere of information. Freedom of expression is in tight connection with media culture in a country, even there are national law provisions, European and international letters and declarations, which is an expression of democratization of her institutions. Pluralism of interests is in danger if there is a partisanship of media, concentration of power from financial oligarchy, selective approach to topics selection and to sources of information and ideologization of media content, especially in countries in transition like Republic of Macedonia is. Then, that influences on decreasing of the awareness of the critical opinion, and media expression can- through reduced, transformed and unilateral approach- to manipulate public opinion. This media reality is pushed to be the ideology of a new collective single- mindedness and is in conflict with the system of values which is the conflict of old and new European values and with no creative approach. Reform of media sphere in Republic of Macedonia in the process of Euro- integration should move towards the democratization of organizational placement, better independency of the editorial policy, elimination of the influence of business oligarchies and political influences, and in the same time standardization of the quality and diversity of media contents.
\end{abstract}

Keywords: Freedom of Expression, Media Reality, Pluralism of Interests, Media Conformism, Idelologization of European Values

\section{Introduction}

"It is a commonly accepted opinion that the integration in EU is not possible without the clear and sound message which should be reflected as the essence of the process of media communication in a democratic world rich with forms of social reaction.In this sense, the European mode represents a type of communication which should be: free, transparent, objective, analytic, and diverse, in other words to enable the expression of the pluralism of interests. In order to promote the European values, the media are facing the task of Europeanization in sense of building standards and criteria which would be enabled with consistent media policy and regulation".(1)

The most relevant aspect to understand the 21 century culture is the media culture which, considering the most spread theoretical idea that the culture is communication, and communication is everything, dominates many forms of the social life. Bearing in mind that the modern world observes, values and develops its culture as culture of communication, accordingly there is no cultural heritage which would be formed by the other side of the media.

Where there is no free media we cannot speak of personal, nor political freedom. It imposes itself as imminent conclusion if the media are prevented to use the freedom of speech by those in power, trying to repress them. "There is no freedom without free media. In addition, the media are not free neither when they are functioning under the influence of others, and not the market laws".(2)

As the basis of the democratization of the society in Republic of Macedonia, the pluralism of the social relations provided a media space which showed really impressive development over the last years. It is evident that 15 years ago very few domestic authors took the liberty to speak of the necessity for differences in opinions, in the sense to legalize pluralism. The unidirectional, canalized and dosed information was the signature of the media messages which had a purpose to manipulate the public through a selected approach within the informative function of the media. The unification, i.e. the establishment of cultural standards and 
criteria once and for all ascertained, led to a state of what is mocked and ridiculed as identity crisis. From this position, instead of being creative laboratories, the media loose the complete sense of the search for new expressive possibilities The exclusion of the black and white valuation in the relation media-culture leads to an expected positioning of this phenomenon - a state in which it will never be possible to say that the media have reached a satisfactory cultural standard, nor categorically determine that the media represent everyone.

If according to the research data it is a known fact that the citizens averagely spend 4 hours in front of their TV screens on a daily basis, the low standard of some radio and TV programs - soap operas, greetings and congratulations, SMS reading, reality TV shows, enters in the prime time of the media space and directly relates with the question of cultural identity and cultural values, i.e. their cultivation and development. These types of shows also belittle the people on a level not respecting their integrity, and humiliate them in order to participate in a show. But we may not disregard that the decision to participate is voluntary. From the journalist practice in the realization of the shows it may be concluded that it is a matter of people who have problems with the social identity and who are prepared to accept even a certain level of degradation only to emerge from anonymity.

It is indisputable fact that the media participate in the creation of the lifestyle through the real possibility to impose a certain lifestyle or different lifestyles in the spare time, through the media space. But, the main concern is whether the medium will go down the line to encourage and stimulate the lowest values of the audience or develop well-thought-out editorial policy caring for the personal integrity through diverse pluralistic programs. Only in this manner the media will be able to create awareness of informed community and of the need for protection and nurture of the cultural values, by respecting and constructively valuing the differences in the intercultural communication of the ethnical communities. Since it is more than clear that where the personal integrity is in jeopardy and the constructed media reality has big influence, we cannot speak of some cultural standards. Therefore, additional liberalization is required also in the media relations and the media policy, particularly in reference with the harmonization of the Macedonian regulations solutions with those of the European Union.

\section{Comparative Review of the Legislation Concerning the Freedom of the Media}

The European information policy and the means proclaimed in it take prominent place in the integration processes, application of democracy, national identity protection and the promotion of cultural differences and pluralism. This EU policy may not be realized without thorough application of Article 10 of the European Convention, where it is stated that everyone has the right to freedom of expression and realization of these rights. Pursuant to the European Convention on Human Rights, the free, independent and plural media take the central stage in the functioning of the democratic societies. The freedom of expression and informing is one of the core principles the democratic society is based on and is essential condition for the development of each person.

The operation of the Council of Europe in the media sector is directed towards the strengthening of the freedom of expression and informing and the free flow of information across the borders. For this purpose it has developed Pan-European political measures and suitable legal and other instruments. In addition, through the formulation of suitable measures, it is a practice that the media laws and policies go in line with the technology, economic and regulative changes in the media sector. A string of declarations of the freedom of expression and informing, agreements, conventions, other binding documents, recommendations, as well as European ministerial conferences for the media are to follow. The priority tasks in the European documents creating the media policy are focused on three main subjects. The first one refers to the media and the democracy. For this purpose, a monitoring of the media concentrations is conducted, the implications of the new communication technologies for human rights and democracy are analyzed and a high level of protection is provided for the holders of the rights, freedom of informing etc. The second subject created by the European media policy is the media in a Pan-European perspective. For this purpose, strategies are being created for greater endeavor for freedom of the media. The third subject is the media and the human rights. For this purpose, information of the media is necessary in reference with legal procedures, acceptable restrictions in respect of release of information and opinions in the media regarding political figures and public officials.

It should be underlined in this comparative review that the freedom of the press in the USA is defined by the US Constitution, the free markets system and the tendency that the law is drafted with the assumption that the regulations are to be circumvented. Even the first amendment of the Bill of Rights to the US Constitution quotes: "The Congress may not create law...limitation of the freedom of speech or press..." (3) This wording ensures the freedom of the press in the US Constitution, the document which defines the government structure and based on which the US laws are drafted. During the first years of the Republic, when this system of inspections and balance was created, the brave journalist community was already established. The daring and feisty press represented influential force in the rejection of the British Crown and led colonial America in a revolution against the British Empire. With the protection of the journalist freedom with the Bill of Rights from 1791, the press grew into reliable force during the first decades of the formation of the nation. Nowadays, the US media are often called the Fourth Estate (along with the three branches of the 
US Government: legislative, judicial and executive authority), a term which implies that the press has equal position with the other Government branches defined with the Constitution. Several crucial court processes represent a turning point in the establishment of the rights of the press to search for information and publish governmental documents or denigrating information on public persons. For example, the Supreme Court of the United States took the side of the journalists instead of the Government when it approved the publication of what later became known as the Pentagon Papers. In addition, the Supreme Court of the United States considered that the first amendment has to protect the media from the laws on defamation - in case the fear of a court procedure and possible material damages discourages the media owners to inform with regards to public matters. In order for a public person to win a defamation case against a respondent journalist, the prosecutor needs to prove "factual malevolence" which the courts define as conscious awareness that the published allegation was untrue or as "rude disregard whether the published information is a lie or not".

The national and international law protect the freedom of expression and informing against all types of censorship and interference by the public authority. This safeguards the freedom, the independence and the pluralism of the media, as well as the journalism ethics and confidentiality of information. The development of the broadcasting and the program content has its frame within the sense of Article 16 from the Constitution of Republic of Macedonia guaranteeing the right and freedom of expression and informing, and of the artistic and cultural creativity. Speaking in broader terms of the radio and TV programs, the cultural identity and the other values as well, the family as a nucleus where the personal identity is formed and where it is continuously developed still has a dominant role in this era of fast technological changes. Therefore, the recommendations of the European Union Commission in the Directive "Television without borders" underline the importance of the so-called family TV watching. Along with the comparative review of the regulative solutions for license issuing and the program offer in Europe, the French law promoting the protection and affirmation of the French language and culture is also significant fro Republic of Macedonia. Also in line is the Canadian law promoting maximal use of the main creative and other resources in Canada. Another good example is the Swedish law defining quotas for original theatrical and artistic national work from the Nordic countries. The law on broadcasting in Republic of Macedonia defines also the principle for preservation and cultivation of the national identity, the language culture and the national opus.

The development of the democracy in a society is in close correlation with the relation of the society with the citizens on one hand, and the development of the informative technical-technological possibilities on the other hand. The democratization arises from the implementation of the above stated relations, and therefore it may not be divided and analyzed by its parts, but the value component lies in its entirety. The two most commonly used democratic forms which are represented in the media in different forms are the representative and the participative form.

The role and the importance of the media in the representative form are best described by the renowned theoretician Blumer, according to whom, in this form of democratization, the media are operating in close correlation with the citizens and their interests. Hence, the most necessary thing for the citizens in the area of informing is the following: "Well informed agents who will be capable of acting efficiently in the analysis of the information environment and who will find reasonable solutions for the problems facing our society nowadays (4). In a state of democratic representation, the media need to create the so-called permissible life and approximate that life to the entire audience. In this manner, the media realize their functions for the account of the public which does not have its own personal role. That means that in a state of democratic representation, the media create participation of the citizens in the public life without their direct involvement, or as the US political theoretician Bernard Cohen said: "The media may not be successful much of the time in telling people what to think, but it is stunningly successful in telling its readers what to think about".(5)

In a state of participative democracy, the media protect in a widest manner the right to participation of the citizens in the entire social life. In this form of democratization, the protection of the citizen and his political, cultural rights is positioned in a limelight.

\section{Three Aspects of the Media Representation of the Democratic Processes in Republic of Macedonia}

The analysis of the 2012 survey in Republic of Macedonia conducted by the Institute for Sociological and Political-Legal Researches in Skopje shows that $92 \%$ of the population is in a daily contact with some of the media. The most popular medium is the television, with $60 \%$ of the total number of people participating in the survey, followed by the press with $25 \%$ and the radio with $17 \%$. Obviously, the research included only the traditional media, and not the new social networks. One person participating in the survey stated: "I watch TV several hours a day, every day. In this manner I am receiving information regarding the happenings in the world. I cannot imagine the world with no TV. I would be totally lost in a world of that kind".(6)

Most of the media offer high quality programs drawing the attention of the audience. Their programs may appeal to everyone's taste and all ages. They elevate the cultural conscience of the users, and simultaneously offer opportunity for relaxation and leisure. The media may be represented as good critics of the government. With the actualization of certain problems in the social structure by one or more media, they constrain the government to take 
measures for their solution, as well as to change its decisions under the public pressure. Nowadays, the government is often inapproachable for the common people. With that, the people are deprived of their democratic right. With this attitude of the government it is very difficult to approach it. The people may express freely through the media and be certain that their message reached the government, if it is addressed to it. An unfavorable side of the media is the possibility to conceal the received information. They have the power to decide themselves what shall be presented to the public, and what shall not. If there is concealing of information, than the citizen is incorrectly or incompletely informed, creating false impression of the happenings in the world. The political inclination in some of them leads to a daily unsubstantiated criticizing of the opposite side. The public is presented with informative content which is not harmful for the political party supported by that medium and also point at increasing of its rating. The most recent analysis show that the most viewed Macedonian medium is TV Sitel, and the most read newspaper is Dnevnik.

If a decade and a half ago it was unthinkable to mention publicly the name of any high ranking state official in Macedonia, even a local one, now it is a common informative element which can be recognized and additionally supplemented with picture and sound, without consequences for the author, naturally if the mentioning is accordingly substantiated. Although, there are cases when a dosed sensationalism directed towards a certain target group in the society for a particular purpose may sneak through. For example, even in 2004 TV Sitel made most open accusations against then-current officials of the coalition government that they propagate from their position failure of the referendum in Republic of Macedonia regarding the new territorial organization of the municipalities, using the money of the citizens. And it was not the standpoint of concrete political persons or parties, but professional standpoint of the medium, i.e. the journalist. Almost simultaneously with the release of this standpoint, there followed a reaction from the other side along with an explanation that the governmental officials are citizens as well and they too can have their own opinion and make their own choice - to vote or abstain, but to also call on to one or the other. The analysis of the debate shows regarding the referendum question on the TV stations A1, MTV, Sitel shows that along with the two diametrically opposed standpoints, a third one emerged, an expert opinion inclining more towards the affirmative than the negative position with regards to the Decision on referendum.

The three democratic standpoints regarding this typically political, but also ethnical matter in its core were put forward for days. The foreign media also tracked these happenings. Since it is a matter of ethnical character as well, we may point out that $\mathrm{BBC}$ qualified the actual interethnic state in Republic of Macedonia by defining the country as "(...) two nations which have virtually no communication between each other".

"This is a match made in hell. The Macedonians are orthodox Slavs, similar with the Serbs, feisty, raw, and characterized by some as having no sense of humor. The Albanians are mainly Muslims, wise, smart, even savvy according to some". (7)

It is important to point out that the three standpoints intensely sensitized the citizen as carrier or supporter of the government comprehended in a pragmatic manner. Therefore, no one else even considered being aside of what was discussed, claimed or denied. The different aspects of the treatment of the referendum matter in the media through forums, debates, analyses and argumentation of the opposite standpoints created critically tuned media audience with rationally built opinions in regards with the mentioned democratic polemics. Thus, the freedom of belief and speech, representing a fundamental base of the democratic processes in general, was confirmed in a most obvious manner.

Within the frames of the case analysis of the media and the democratization of the society, another social-political situation on a totally different subject - the premature presidential elections which were conducted just few months before the referendum in 2004 ought to be explained. Those abstaining from the referendum on the new territorial organization propagated to the people to vote long before the elections, and the supporters of the referendum quietly plotted a boycott of the elections with a combination plus from the nongovernmental national and international factor, which was far more and suggestively expressed before and during the referendum. In this situation, the Macedonian media represented Hyde Park of what the voting and the boycott mean to the state and the citizen. In the course of this, different truths were presented, depending who supports them and for which purpose. In the sense not to be closed up for being honest and open, simple or complex, depending on the reasoning, this matter was covered in the media by: politicians, intellectuals, independent experts and other public personas. The media were once again in the center of this pre-election "volcano" and played their socially determined role.

With the democratic approach in the treatment, the media in Republic of Macedonia revealed and will yet be revealing numerous scandals, corruptions, legal malpractices and touching life stories for starving, abandoned, left or forgotten people. They stirred up the public opinion and reminded on some forgotten moral norms, standards and criteria which are the foundation for every healthy society with a democratic signature. Some individuals immediately rushed to address them with qualifications that it is not right to devalue persons in this manner and bring down their integrity and credibility before the courts give their judgment. The fact that they brought down a part of the total social integrity was not of relevance for them and they forgot it, intentionally or not. 


\section{The Pluralism in the Informative Matters in the Macedonian Media Space}

The definition of what is pluralism of the informative matters in the media communication involves enabling maximal flow of different, opposed opinions in reference with the relevant aspects of a social matter, and that information quality precisely is the element of the analytical genres. Often, the "other side" is missing in the journalistic stories.

The focusing on the analysis in the central daily-informative shows is justified for several reasons. Firstly, because they represent a concentrated form of realization of the informative function of the media. Secondly, they have high rating compared to the other programs in the periods when the TV stations have highest number of viewers. From a methodological point of view, the analysis in the program week is realized in two levels:

- All of the features in the news are analyzed from a point of view of the following characteristics: measuring of the time of each separate story; classifying the subject matter of the programs (areas of the social living the stories refer to) measuring of the time representation of the different political subjects (political parties and governmental segments).

- In order to compare the manner of reporting of the different media - two events, two features are analyzed from the point of view of: the language being used to explain the event (use of attributes, emotional expressions, comments etc.); representation of opposed opinions; presentation of additional facts and information in reference with the events; use of quotations during the reporting; use of sources (if and how the sources are used, quoting and paraphrasing); use of footages (authentic, archive or other medium); sequence of analyzed features in the news; and the context the medium uses to report on the subject (positive, neutral or negative).

The criteria for selection of two events are that they should have broader social meaning and be present in the informative treatment if not on all of the media, than at least on part of them.

In general, the analysis of the news on the five national television stations in several phase program weeks in 2011 showed that the Macedonian audience is formally offered with high degree informative pluralism, as with regards to the subjects constituting our daily routine, so with regards to the representation of the institutions of the government system and the political parties. However, it may be acknowledged that the media understand the pluralism (propulsion of different opinions) as transfer of a quantity of information rather that as quality of data processing. This is evident from the dominance of the level of being informed (presentation), compared to the level of analytics (creation) in the news, i.e. greater representation of the informative compared to the analytical genres. Particularly in some TV stations (Sitel, A1) the political inclination is expressed in the general and the separate announcements of the features, and with the use of attributes, emotional expressions and comments, the informative element of the news instead of neutral acquires positive or negative media context. The analytical creation in the daily-informative shows is often reduced to presentation of the editor's opinion reflecting the editorial policy of the medium, without simultaneously present opposite opinions and additional facts and information regarding the events, which would objectively support the comment.

When informing of the social-political events, the media in Republic of Macedonia use a lot of imprecise and suspicious resources of information, unmarked and illustrative materials without known background, features with conflict character illustration only one side, as well as unsigned articles. The analysis also show that the unnamed or generally defined resources are most often used by the media to release unconfirmed information regarding the national stage, but also when informing on events happening outside Macedonia.

\section{The Media and the Influence of the Political Elites}

The political parties, especially those governing, have great influence over the freedom and independence of the media expression. Pursuant to the media experts and the previous researches, the Macedonian Radio Television as a public national service in Macedonia was and still is under the influence of the governing political elites. On the other hand, the abrupt commercialization ant politicization of the other TV stations with national concession also drastically lowered the rating and the audience of the most influential media - televisions. The Macedonian citizens watch foreign programs more and more, and the programs of the Croatian television are the most viewed in the urban areas according to some researches.

Some media experts underline that the influence of the government over the public service MTV was at the highest point from 1992 to 2002, and is still present today, even though with a lower intensity. However, it is a fact that the political elites realized that the abuse of the public service and the voting body translates into political defiance. In the meantime, the rating of MTV and its influence among the population dropped down, which led to decrease of the direct political influence as well. The practice shows that a more realistic estimation is being dimensioned regarding the extent to which it is of assistance for the governing politics and the political forces in opposition. In particular, the influence of the parties over the media increases during elections. "Now the politic influence is cautious from both of the opposing options in the Macedonian block, excluding the influence of the Albanian governing block, where it is very notable". (from an interview made on 10 March 2012).

Bodo Hombach, executive director of the German company WAZ Media Group says in his article "Editorial 
independence in South-East Europe" which refers to the freedom and independence of the media in South-East Europe: "In order for the media to be free and independent, they have to be economically independent. Everyone should be suspicious of publishers who are not motivated by economical interests. Regardless of who the owner of the medium is, if he is not interested in money, than his motives are suspicious". (8)

The media in Macedonia are overdosed with daily politics, i.e. more and more often they take a side regardless of whether it is a matter of political interest or commercial struggle for profit. The analyses in Macedonia, as part of the comparative analyses of the media in a period of transition, political tensions and election wars from the research by the South East European Network for Professionalization of the Media and the Macedonian Media Institute with regards to the ethics and journalism in South East Europe in 2010 show that as much as $90 \%$ of the journalists call the medium owners before publishing the information and that behind almost every medium there is certain economical-politic group and interest dictating the manner of informing and processing of the subjects. According to this research, some are trying to hide behind objective informing, while others quite openly do it. As the most obvious example we may name A1 which "(...) due to the direct influence of the owner over the editorial policy, was abandoned in only a year by the chief executive editor and several journalists-editors".(9). The editor of a television station and a weekly newspaper with a 20-year experience says: "The most recent example when two people left A1 happened due to the pressure and the influence of the television station owner. Usually, the editor and the owner are the persons making pressure in a polished and cultural manner".(10) However, the Macedonian citizens recognize also the influence of the leaders of political parties who are the owners of Sitel and Kanal 5. The pressures are particularly obvious during elections, when the decision of whether something shall be published or not depends on the politic inclination of the media, the closeness to one or other political option or editorial policy, as well as on the financial relations between the owner and the political party. The media reality shows that there are many cases when serious matters are being hushed up due to pressure from the political and economical circles. This is also confirmed with the interviews with several journalists. According to their analysis, one radio-journalist had such experience by having many pressures, being taken off program and experience "program embargoes". The opinion of the majority of his colleagues is that the media are profiled as governmental or are in function to protect the political or business interests of the owners.

"All of the media in our country are politically profiled. Everyone who follows them may precisely determine which medium is inclined to which party. If the owner or the main financer is involved in a political battle, it is natural that he will use the medium for that purpose, but will also misuse the medium and the journalists. The journalist who will follow those happenings will not be able to go against, since it would provoke his dismissal" - says a TV journalist. (11)

The journalists more and more comment that besides being afraid of the owners and editors to defy the pressures, they have no faith in the professionalism of the Journalist Association which is their professional organization in Republic of Macedonia.

\section{The Macedonian Media and the Confidence of the Citizens}

The citizens of Republic of Macedonia have no confidence in the government and the media, as it is shown from the researches in the previous years by most of the Macedonian research institutes, as well as the UN development program. Or, more precisely, over $70 \%$ of the citizens have no confidence in the journalists and the media houses - radio and television stations and the newspapers. Only $25 \%$ of the surveyed believe to be accurately and objectively informed of the political matters, and as much as $67 \%$ have no confidence when they are reporting on corruption. Before receiving the candidate status for EU, the results for the Macedonian journalism was quite the opposite. Back then, nearly $60 \%$ of the population had confidence in the media.

Considering the influence of the media in the formation of the European values, the question why the Macedonian media lost their credibility deserves a special analysis. It has been said on many public forums, multiple articles, analyses and researches that the influence of the media is declining, and it is not as a result from the additional informing through the internet, but due to the low professional and ethical standards above all. Some journalists, analysts and researches of the Macedonian media space have warned us for quite some time that the Macedonian journalism is not moving in a good direction. The first indications that there is something dramatic happening in the relation public - media were obvious since the audience ratings of many influential TV and radio stations dropped rapidly, immediately followed by a drop of the circulation of all daily and weekly newspapers. These are merely the consequences of a long-term agony in the Macedonian journalism which began in 1997, showing its more obvious features in the crisis-struck 2001 and particularly in 2002 and with small oscillations of improvement lasting even today. This dramatic period was crucial in order to make a critical turn towards the professionalism and ethics, since it did not happen after 1995/96 when there was true pluralisation of the media space and invasion of new media. Instead of professionalization, quality and ethics, the era began of abrupt commercialization and politicization of the media and constant drop of the moral, ethical and professional standards and principles.

The new restructuring of the ownership of the media and the indifference of the state for the permanent crisis of the public service MRTV, as well as the lack of precise legal 
regulation caused degradation of the Macedonian journalism. The long-term economic crisis, the crime and the corruption led to lack of confidence in all institutions of the system. The journalism did not have the strength to oppose it with high professionalism and personal courage. And most importantly, it had no critical public opinion and independent legal apparatus behind it. Practically, it is a great issue if the Macedonian journalism was even prepared in terms of personnel and technical equipment to oppose this social-political and economic state, the organized crime, the perfidious political elites, the unlawfulness, the business oligarchies and the new political ambitious media owners whose primal business is not the newspapers and televisions, but they merely serve them for concentration of power for political influence and suspicious business deals. In these kinds of circumstances, the Macedonian journalism accepted the role of passive observer and stereotype informer. The media failed to discover the reasons for the crisis in 2001 to this date. Even the separate successes in reference with some issues regarding bribery, corruption and crime go by silently since they have no epilogue, no judicial nor moral conclusion.

The doors of populism in 2001 did not close with the ending of the war crisis. On the contrary, the vulgar commercialization of the media began immediately and even more noticeably. The unconscionably low prices of the advertisements on the television and radio stations gave rise to the underground battle for advertisements, degrading the businesses. The battle to survive with low prices of the newspapers and the advertisements made the journalism a degrading profession which not only fell below the dignity of the guild, but entered deeply in the political underground. The intense invasion of hundreds TV and radio stations, 5 national television stations, 11 national newspapers and over 30 weekly magazines devalued the already poorly established media market down to the true value of media product. The columnists, independent intellectuals, university professors openly accepted and to some level promoted the populist variant in the media and began openly flattering the audience.

In such state of the media, those in the Macedonian journalism who rely on the professionalism and the ethical standards do not differ from the media surfing the wave of commercialization and sensation. On the contrary, the dilemma to "yellow" the pages is evermore present since it is becoming the only recipe for surviving and enduring in a state of disorganization of the rules. The chief editors know the formula to attract bigger audience of viewers, listeners, readers, as well as the recipe for more advertisements. It is very simple, the first in line are the interethnic and international matters or the international community, keeping the tension with the phenomenon of the "eternal conspiracy" against Macedonia. Out of the analysis of the media programs it may be confirmed that one daily newspaper with a clear conscience published on the front page an article with the following title - "Elderly man paid 4 times and got sexual services with a minor only once", or the question how the poor sleep under the bridges to be raised at full volume on the TV news, and the candidature of Macedonia in EU to be announced towards the end of the news or on the last page. Then we enter the phase of most serious research journalism, as the case with the secret Swiss accounts of the President of the state. And contrary to the standards of the word media professionalism, the President has not been asked on anything, since it is known that "he will circumvent the truth". It is par excellence journalism which "maligns" even hundreds of persons, and such unprofessional media stories are called portraits by some Macedonian journalists.

\section{Conclusion}

A great influence in the formation of the European values in Republic of Macedonia has the freedom of informing and the development of the media systems. There is an inconsistency, contradiction and ambiguousness in the realization of this function. On one hand, there is a developed media network, and on the other hand, most media are qualified with suspicious quality of the presented media content. Developed own production is lacking, the sensationalism is being promoted, and the popular culture and citizen values are exposed uncritically.

The communicology, but also the culturology analyses point out that the crisis of the national production continues and intensifies. The difficulties in fulfillment of the censuses for own production and program from the local area, which is a characteristic of the concessionaires not only from the smaller cities, but also of some radio and TV stations from Skopje, are the consequence from the slow liberation from the inertia to rebroadcast foreign programs and content without clear program pattern. In this sense, there is a necessity for development of program content which would cover the cultural events in the local environment. Thus, almost all media perform politicization of the program, and from 16 to 24 hours most of the TV and radio program are highly packed with informative matters. In fact, the true challenge in Macedonia is the stimulation of own audio-visual production. One must participate in the European cultural communication with authenticity, or else there is a danger from total marginalization or its transformation in a polygon of cultural influence from the neighboring countries. The equation with foreign programs on a language and cultural base is not only a certain cultural ghettoization, but also damages the multiculturalism. The clear definition of the informative, educative and cultural mission of the media has a primary importance in the prevention of the cultural imitation and manipulation of the public opinion.

In fact, Republic of Macedonia has not entered the process of media establishment and creation of elevated audience of readers yet. There is no competent and objective ranking of the electronic media and newspapers in accordance with the high achievements of the professionalism and what signifies objective and ethical 
journalism. The viewers and readers have yet to identify the true values and thus choose their medium. The media literacy and education should strive to transform the passive relation of the audience with the media in an active, critical engagement capable of challenging the traditions and the structures of the privatized, commercialized media cultures and finding new avenues of the citizen speech. The media education encourages a curious approach to the world of the media, which implies that it is not necessary having the right answers, but asking the right questions and the result of it shall be a lifelong ability of the citizen to differ, interpret and analyze the media messages. Naturally the attraction of the sensation of the yellow press shall always have its circulation primacy. However, here, as in the world, there are certain rules, especially who advertises where and it is particular and important rating, not accounted for in Republic of Macedonia. The moment when the big and esteemed companies which are the major advertisers and consumers of the advertising space will recognize the true target groups where they need to present their advertisements and messages, will be the moment of the true rating of the media. As things stand now, the number of readers and the rating of the media is determined with speculative methods, with simulated and imprecise researches of the media market by suspicious agencies on which the companies are relying.

The need of completely informed citizen with a critically tuned conscious and the need of - culture of creativity should be the leading principles in the operation of the media through complete realization of the informative, educative and leisure-recreational function and hence respect of the media standards and criteria: diversity of the subject and program content, the pluralism in the realization of the media messages, objectivity, comprehensibility and correctness in the construction of the media content and observance of the ethical principles towards the informing resources and the media audience.

\section{Documents Used}

- $\quad$ Bill of rights, (1791), Constitution of USA.

- Constitution of Republic of Macedonia.

- Law on broadcasting in Republic of Macedonia.

- Analysis of the program content of the TV stations: MRTV, Sitel, A1, telma, Kanal 5.

- Analysis of newspapers: Dnevnik, Utrinski vesnik, Vest.

- Interviews with journalists, media experts and representatives from the Journalist Association of Macedonia.

\section{References}

[1] Siljanovska, Liljana (2007), The impact of media on the formation of European values in Republic of Macedonia, Arberia Design, Tetovo, pp.16

[2] Fransis,Bal (1997), The power of media, Clio, Beograd,pp15

[3] First amendment, Bill of Rights, US Constitution, 1791.

[4] Kuncih M, Astrid Cipfel (1998), Introduction to publication and communication sciences, Fondation "Fridrix Ebert", Skopje,pp 101

[5] Ibid:130

[6] Dnevnik, October, 25, 2012

[7] BBC radio, March19, 2004

[8] Dnevnik, June 19, 2005,pp4

[9] Interview with expert from Macedonian Media Institute, august5, 2010.

[10] Interview with a TV editor,august, 18, 2011

[11] From the interviews with the journalists, mart- march 2012. 